Miscelánea 



\title{
UNA APROXIMACIÓN A LA REGULACIÓN DE LAS FUNDACIONES BANCARIAS
}

\author{
Autores: Miguel Martínez Muñoz ${ }^{1}$ \\ Doctorando en Derecho (Beca FPU-Derecho Mercantil) \\ Universidad Pontificia Comillas \\ Álvaro Chapa Sánchez del Corral \\ Graduado en Derecho y ADE (E-3) \\ Universidad Pontificia Comillas
}

\section{Resumen}

El presente trabajo tiene por objeto analizar el régimen jurídico de las fundaciones bancarias tal y como éstas han quedado reguladas por la reciente Ley 26/2013, de 27 de diciembre, de cajas de ahorro y fundaciones bancarias. La norma, de muy reciente publicación, aborda en su Título II una figura novedosa para el ordenamiento jurídico español pero de una importancia capital en todo el sistema financiero en la medida en que estas fundaciones se erigen en los auténti-

\footnotetext{
1 mmmunoz@der.upcomillas.es

2 alvarochapasc@gmail.com
} 
cos protagonistas que se encuentran detrás de algunas entidades bancarias debido al elevado porcentaje de participación en el capital de éstas.

Palabras claves: fundación bancaria; caja de ahorro; transformación; supervisión y control.

An approach to the regulation of banking foundations

\begin{abstract}
This paper examines the legal framework for banking foundations in the context of how they have been regulated by the recent Law 26/2013, December $27^{\text {th }}$, of saving banks and banking foundations. This recently regulation establishes in Title II a new element in the Spanish legal system that has substantial importance for the financial system because these foundations established in reality have effective control over the banks due to the high percentage of share capital that the banking foundations hold in these banks.
\end{abstract}

Key words: banking foundation; saving bank; transformation; supervision and control.

Recibido: 29-04-2014

Aceptado: 04-06-2014

\title{
1. INTRODUCCIÓN
}

La Ley 26/2013, de 27 de diciembre, de cajas de ahorros y fundaciones bancarias (BOE núm. 311, de 28 de diciembre de 2013) (en adelante, "la Ley") tiene como objetivo ofrecer una solución a los problemas financieros surgidos a lo largo de las últimas décadas en el marco de las cajas de ahorro. Durante los últimos años, se establece en la Exposición de Motivos de la Ley, ha sido necesaria una profunda intervención de los poderes públicos en todo el tema del saneamiento y reestructuración de buena parte de las cajas de ahorro cuya situación financiera había llegado a comprometer muy gravemente el conjunto de la estabilidad financiera en España ${ }^{3}$. En este marco, la nueva Ley ha previsto normativamente las fundaciones de carácter especial al objeto de permitir la separación completa

${ }^{3}$ RUBIO TORRANO, E., "Fundaciones bancarias y cajas de ahorros", Revista Doctrinal Aranzadi Civil-Mercantil (núm. 6, 2013), versión electrónica (BIB 2013/1559), p. 1. 
de la actividad bancaria y la obra social de las cajas de ahorro, surgiendo pues las denominadas fundaciones bancarias que son objeto de este trabajo. La Ley dedica buena parte de su texto a regular las fundaciones bancarias mediante el establecimiento de un régimen similar al ya previsto para las entidades de crédito en un contexto complejo, en el que se entremezclan competencias estatales con competencias autonómicas y en donde se trata con respeto las cuestiones definidas como básicas para la regulación del sector crediticio español.

En este sentido, después de tratar el concepto de fundación bancaria, la Ley establece los supuestos de transformación de las cajas de ahorro en estas fundaciones para, seguidamente, ordenar un marco jurídico cuyo objetivo es garantizar que las fundaciones bancarias actúen con los niveles de profesionalidad, independencia, transparencia y eficiencia máximos, sin que en ningún caso se pueda poner en peligro la solvencia de las entidades en las que participan. Asimismo, establece determinadas disposiciones que sólo serán de aplicación a aquellas fundaciones que tengan una participación cualificada o de control en una entidad de crédito, es decir, se establece un régimen escalonado en lo referente a las obligaciones de las fundaciones bancarias.

Pasamos pues, de esta forma, a un panorama totalmente distinto al que existía hasta la entrada en vigor del nuevo régimen. Así, de un sector en el que coexistían cajas de ahorro, cajas de ahorro que individual o conjuntamente ejercitaban de forma indirecta la actividad financiera a través de un banco, fundaciones de carácter especial y sistemas institucionales de protección (SIPs), se pasa a un escenario en el que conviven únicamente cajas de ahorro, fundaciones bancarias y fundaciones ordinarias ${ }^{4}$.

\section{CONCEPTO DE FUNDACIÓN BANCARIA}

La Ley define, en su art. 32, a la fundación bancaria como "aquella que mantenga una participación en una entidad de crédito que alcance, de forma directa o indirecta, al menos, un 10 por ciento del capital o de los derechos de voto de la entidad, o que le permita nombrar o destituir algún miembro de su órgano de administración”. Continúa la norma comentada estableciendo que las fundaciones bancarias tendrán finali-

\footnotetext{
${ }^{4}$ HIDALGO ROMERO, R. y PIAZZA DOBARGANES, L., "Consideraciones preliminares sobre la regulación proyectada de las fundaciones bancarias", Revista Aranzadi Doctrinal (núm. 11, 2013), pp. 29. 30; LÓPEZ JIMÉNEZ, J. y NARVÁEZ LUQUE, A., "Ley de Cajas de Ahorros y Fundaciones Bancarias: la expulsión de las cajas de su paraíso financiero", Diario La Ley (núm. 8246, 7 de febrero de 2014), versión electrónica (LA LEY 140/2014), p. 1, se pone de manifiesto que las cajas de ahorro han pasado de ser actores protagonistas a quedar relegadas a un papel testimonial en apenas un lustro, de tal suerte que las subsistentes en la actualidad, con la excepción de dos minúsculas entidades que mantienen la estructura tradicional de la caja de ahorro, se han valido de bancos instrumentales para el desarrollo indirecto de su actividad financiera en los términos del Real Decreto Ley 11/2010.
} 
dad social y orientarán su actividad principal a la atención y desarrollo de la obra social y a la adecuada gestión de su participación en una entidad de crédito. Se ordena, asimismo, que en la denominación de estas fundaciones se haga constar la expresión de "fundación bancaria".

La propia Exposición de Motivos atestigua cómo la regulación básica de estas fundaciones se inspira en la figura de las fundaciones de carácter especial, recogidas en el Real Decreto Ley 11/2010, de 9 de julio y que tenían por objeto permitir la separación completa de la actividad bancaria y la obra social de las cajas de ahorro ${ }^{5}$. Asimismo, se pone de relieve el carácter novedoso de esta figura en el ordenamiento jurídico español y se dan una serie de razones justificativas de su regulación con el carácter de básico por parte del Estado. En efecto, entre estas razones, destaca la consideración que tiene la Ley de que las fundaciones bancarias son un "actor principal" presente en la mayoría de las entidades de crédito de nuestro país, de tal forma que se incrementa la posibilidad de que un funcionamiento inadecuado de estas entidades tenga consecuencias para la estabilidad de todo el sistema financiero. Por otro lado, en tanto en cuanto estas fundaciones ostentan participaciones significativas, e incluso de control, en entidades financieras, el legislador no puede ignorar el régimen jurídico de aquéllas, estableciendo, en consecuencia, una regulación similar a la que se ha dictado ya en relación con el resto de entidades de crédito para garantizar así una adecuada ordenación del crédito en nuestro país ${ }^{6}$.

De hecho, antes de las razones apuntadas sobre la conveniencia de la regulación de las fundaciones bancarias, debemos preguntarnos por qué se han

${ }^{5}$ En este sentido, el art. 6 Real Decreto-ley 11/2010, de 9 de julio, establece: "Artículo 6. Transformación de cajas de ahorros en fundaciones de carácter especial. 1. Las Cajas de Ahorros podrán acordar la segregación de sus actividades financiera y benéfico-social mediante el régimen previsto en este artículo en los siguientes casos:

a) Conforme a lo previsto en el apartado 3 del artículo anterior.

b) Como consecuencia de la renuncia a la autorización para actuar como entidad de crédito y en los demás supuestos de revocación.

c) Como consecuencia de la intervención de la entidad de crédito en los supuestos previstos en la Ley 26/1988, de 29 de julio, de disciplina e intervención de las entidades de crédito.

A tal efecto traspasarán todo el patrimonio afecto a su actividad financiera a otra entidad de crédito a cambio de acciones de esta última y se transformarán en una fundación de carácter especial perdiendo su condición de entidad de crédito.

La fundación centrará su actividad en la atención y desarrollo de su obra benéfico social, para lo cual podrá llevar a cabo la gestión de su cartera de valores. La fundación deberá destinar a su finalidad benéfico social el producto de los fondos, participaciones e inversiones que integren su patrimonio. Auxiliarmente, podrá llevar a cabo la actividad de fomento de la educación financiera.

2. El acuerdo al que se refiere el apartado anterior estará sujeto al cumplimiento de los requisitos previstos para la constitución de fundaciones y supondrá la transformación de la Caja en una Fundación de carácter especial. La segregación de la actividad financiera, por su parte, se regirá por lo establecido en la Ley 3/2009, de 3 de abril, sobre modificaciones estructurales de las sociedades mercantiles".

${ }^{6}$ RUBIO TORRANO, E., cit., p. 2. 
creado estas entidades. La respuesta se deduce claramente de una detenida lectura de la Ley pues se observa cómo este texto normativo pretende controlar el tamaño de las cajas de ahorro para impedir así que sean lo suficientemente grandes como para que adquieran carácter sistémico, lo cual, encaja perfectamente con las exigencias previstas en el Memorando de Entendimiento sobre condiciones de política sectorial financiera, en cuyo punto 20 del Anexo 2, "Condicionalidad", se establecía el compromiso del Gobierno español de preparar normas "para clarificar el papel de las cajas (...) en su calidad de accionistas de las entidades de crédito con vistas a una eventual reducción de su participación a niveles no mayoritarios"?.

Es aquí donde reside el origen y el fundamento de las fundaciones bancarias en la medida en que se dispone que aquellas cajas de ahorro que crezcan por encima de los límites permitidos perderán su licencia bancaria, deberán transmitir su actividad financiera a una entidad de crédito y habrán de transformarse en fundaciones bancarias. Es decir, las fundaciones bancarias se crean como solución a un crecimiento desproporcionado de las cajas de ahorro y para separar así la actividad financiera y la obra social, motivos éstos por los cuales la Ley establece unos supuestos obligatorios de transformación de las cajas de ahorro en fundaciones.

En este sentido, además de buscarse el control de aquellas cajas de ahorro que adquieran un determinado tamaño, también se pretende separar completamente las actividades financieras de aquellas otras propias de la obra social de la caja. No se debe olvidar que las cajas de ahorro tienen una naturaleza de fundaciónempresa de carácter especial y, dentro de la tipología de las fundaciones, se considera que las cajas de ahorro son fundaciones mixtas, con fines dotacionales y funcionales ${ }^{8}$. Así, las cajas de ahorro son un tipo de fundaciones que desarrollan una actividad empresarial para la obtención de recursos suficientes destinados a dar cumplimiento a los fines propios de la fundación, los cuales pueden tener una

${ }^{7}$ SÁNCHEZ-CALERO, J., "Anteproyecto de Ley de cajas de ahorro y fundaciones bancarias”, Revista de Derecho Bancario y Bursátil (núm. 129, 2013), p. 324.

${ }^{8}$ Sobre la naturaleza jurídica de las cajas de ahorro véase, entre otros, DIEZ-PICAZO, L., "Sobre la naturaleza jurídica de las cajas de ahorro", Revista jurídica Universidad Autónoma de Madrid (núm. 8, 2003), pp. 199 y ss.; ARAGÓN REYES, M. y otros, El régimen jurídico de las Cajas de Ahorros, Caja Madrid, Madrid, 1991, p. 120; MARTÍNEZ MERCADO, M., "Las cajas de ahorro: propiedad y ejercicio de las cuotas participativas ante el RD 11/2010. ¿Fin de su naturaleza jurídica?, Revista de Derecho Bancario y Bursátil (núm. 121, 2011), pp. 140 y ss.; EMBID IRUJO, JM., "El ejercicio de actividades empresariales por las fundaciones (fundación-empresa y fundación con empresa): su significado en el régimen jurídico de las Cajas de Ahorros en España", Perspectiva del Sistema Financiero (núm. 91, 2007), pp. 29 y ss.; SÁNCHEZ-CALERO, J., "El Real Decreto-Ley 11/2010 y la "mercantilización" de las cajas", Revista de Derecho Bancario y Bursátil (núm. 121, 2011), pp. 177-179; CAÑABATE POZO, R., El régimen jurídico de la fusión de Cajas de Ahorros, Unicaja-Marcial Pons, Madrid-Barcelona, 2006, pp. 159-168; LA CASA GARCÍA, R., "Los modelos de organización institucional de las cajas de ahorro", Revista de Derecho Bancario y Bursátil (núm. 131, 2013), pp. 16-19. 
naturaleza heterogénea: fines sociales, culturales, asistenciales, etc ${ }^{9}$. En este sentido, la actividad que desarrolla una caja de ahorro es mixta, toda vez que realizan actividades de crédito en interés de sus inversores y, al mismo tiempo, tienen una finalidad social, en la medida en que los beneficios obtenidos se destinan al desarrollo de obras sociales ${ }^{10}$.

Por tanto, se aprecia aquí la existencia de una tensión entre el riesgo empresarial inherente a la actividad financiera que desarrolla la caja y la administración del patrimonio fundacional desde la perspectiva de los fines fundacionales que conducen a una gestión prudente y, en todo caso, conservadora del patrimonio de la entidad ${ }^{11}$. Precisamente, con la nueva regulación dada por la Ley, desaparecerá esta tensión existente entre la actividad financiera "de riesgo" y la actividad fundacional "de conservación" en la medida en que la primera actividad se traspasará a un banco y quedará la segunda radicada en la fundación, bancaria u ordinaria, que surja del proceso de transformación, destinándose así los recursos obtenidos por la fundación de su participación en el capital social del banco para el desarrollo de las actividades de la obra social.

\section{SUPUESTOS DE TRANSFORMACIÓN EN FUNDACIONES BANCARIAS}

Los arts. 34 a 36 de la Ley regulan la obligación de transformación de las cajas de ahorro y fundaciones ordinarias en fundaciones bancarias. En concreto, el art. 34 nos brinda el principal motivo de fondo que hay detrás de la obligación de la transformación y que hemos comentado anteriormente, a saber: evitar el crecimiento desproporcionado de las cajas de ahorro. En efecto, la Ley prevé la transformación en dos supuestos concretos: (i) cuando el valor del activo total consolidado de la caja de ahorro, según el último balance auditado, supere la cifra de diez millones de euros; o (ii) cuando la cuota en el mercado de depósitos del ámbito territorial

9 Un análisis de la Memoria elaborada por la CECA sobre la Obra Social en 2012 (disponible en http://www.ceca.es/rsc/pdfs/Memoria_OBS2012.pdf) nos muestra cómo en el ejercicio 2012, último ejercicio del que constan datos, las cajas de ahorro con obra social invirtieron aproximadamente 818,59 millones de euros en distintas actividades sociales: asistencia social y sanitaria (48.4\%), cultura y tiempo libre (29\%), educación e investigación (17.1\%) y patrimonio histórico, artístico y natural (5.5\%).

${ }^{10}$ LEÓN SANZ, F.J., "La reestructuración del sistema financiero español: la transformación de las Cajas de Ahorro", en Las reformas de las sociedades cotizadas y del sistema financiero 2008-2009, Monografías Coediciones Aranzadi, Aranzadi, 2014, versión electrónica (BIB 2014/5110), p. 3; TITOS MARTÍNEZ, M., "La Obra Social de las Cajas de Ahorros y sus perspectivas de futuro", Extoikos (núm. 8, 2012), pp. 68-72, recopila datos de las cajas de ahorro en el período 1947-2012 y concluye que en todos esos años, las cajas lograron unos beneficios totales de 138.623 millones de euros, de los que destinaron a actividades de obra social el 25\%, es decir, cerca de 34.908 millones de euros.

${ }^{11}$ LEÓN SANZ, FJ., cit., p. 4. 
de actuación sea superior al 35\% del total de depósitos ${ }^{12}$. Además de estos dos supuestos, la Exposición de Motivos hace referencia a un tercero al precisar que, además de transformarse en los casos de superación de los límites legales permitidos, también tendrán que transformarse aquellas cajas que a la entrada en vigor de la Ley estén ejerciendo su actividad financiera a través de un banco, es decir, de forma indirecta ${ }^{13}$. Precisa la Ley que, en estos casos, la caja de ahorro ya no ejerce actividad financiera alguna y se encuentra centrada únicamente en la acción social, careciendo por tanto en estos casos de toda justificación el mantenimiento de la licencia bancaria ${ }^{14}$. Esta mención en la Exposición de Motivos tiene su reflejo en la Disposición Transitoria Primera de la Ley, la cual establece una serie de particularidades para las cajas de ahorro de ejercicio indirecto ${ }^{15}$.

Pues bien, si concurre alguno de los dos motivos ex art. 34.2, la caja de ahorro deberá traspasar todo el patrimonio afecto a su actividad financiera a otra entidad de crédito a cambio de acciones de esta última y procederá a su transformación en una fundación bancaria, siempre y cuando se cumplan los requisitos del art. 32 para ser tal, o en una fundación ordinaria en caso contrario, con pérdida en ambos casos de la autorización para actuar como entidad de crédito ${ }^{16}$. Se observa así cómo la fundación bancaria u ordinaria resultante de la transformación de la caja de ahorro se convierte en accionista de la entidad de crédito que recibe el

${ }^{12}$ Precisa el art. 34.3 que si la entidad pertenece a un grupo a los efectos del art. 42 del Código de Comercio, los supuestos de transformación se referirán al balance y cuentas consolidadas, afectando en estos casos la obligación de transformación a todas las cajas de ahorro del grupo, las cuales podrán transformarse en tantas fundaciones como cajas existan.

${ }_{13}$ Art. 5 Real Decreto Ley 11/2010, de 9 de julio.

${ }^{14}$ La Ley califica a estos casos de "anomalía”. En este sentido, véase LA CASA GARCÍA, R., cit., p. 20.

${ }^{15}$ Los supuesto previstos en esta disposición son, a grandes rasgos, los siguientes: (i) las cajas de ahorros de ejercicio indirecto deberán transformarse en el plazo de un año en una fundación bancaria u ordinaria; (ii) las cajas de ahorros que estén incursas en causa legal de transformación en fundación de carácter especial de las reguladas en el art. 6 Real Decreto-ley 11/2010, de 9 de julio, contarán con el plazo que reste de los seis meses previsto en el art. 35.2 de la Ley desde que hubiesen incurrido en dicha causa; (iii) las cajas de ahorros que lleven incursas en causa legal de transformación en fundación especial un período superior a seis meses deberán transformarse en fundación bancaria u ordinaria antes de tres meses a contar desde la entrada en vigor de la Ley; (iv) las cajas de ahorros que sin estar incursas en causa legal de transformación en fundación especial hayan iniciado el procedimiento voluntariamente deberán transformarse en fundación bancaria u ordinaria antes de seis meses y $(\mathrm{v})$ en caso de que no se respeten los plazos establecidos para proceder a la transformación, la misma operará ipso iure, produciéndose la disolución de todos sus órganos y baja en el registro especial de entidades de crédito del Banco de España.

${ }^{16}$ HIDALGO ROMERO, R. y PIAZZA DOBARGANES, L., cit., pp. 30-31: "Tomado en consideración los umbrales exigidos (...), cabe concluir que tal obligación afectará a la práctica totalidad de las actuales cajas de ahorros. Máxime teniendo en cuenta que la disposición transitoria cuarta [la del Anteproyecto] dispone que las cajas de ahorros que a la entrada en vigor de la ley ejerzan su actividad como entidad de crédito a través de un banco (entre las que están las más importantes) habrán de transformarse también en fundación bancaria (...). Por tanto, sólo en casos puntuales no operará la obligación de transformación, sin perjuicio de que, tales cajas podrían transformarse voluntariamente en fundaciones bancarias". 
patrimonio afecto a la actividad bancaria de la caja, quedando las funciones de la acción social radicadas en la nueva fundación ${ }^{17}$.

La Tabla 1 siguiente nos muestra el proceso de reestructuración que han tenido las cajas de ahorro desde 2009 hasta la actualidad.

Tal y como podemos apreciar, la mayor parte de la reestructuración del sector de las cajas de ahorro se produjo en el período 2010-2011 con la entrada en vigor del ya mencionado Real Decreto Ley 11/2010, de 9 de julio, norma que introdujo las fundaciones de carácter especial y que constituye la norma cuya continuación pretende la Ley ${ }^{18}$. De esta forma, el panorama desde la actualidad ha cambiado completamente, toda vez que de un total de 45 cajas de ahorros que había a finales del año 2009, 43 han participado o se encuentran participando en algún proceso de consolidación. Esto, en volumen de activos totales medios, representa el 99,9\% del sector. Además, el sector ha pasado de estar constituido por 45 entidades, con un tamaño medio de 29.440 millones de euros a finales de 2009, a estar formado por 13 entidades o grupos de entidades, con un volumen medio de activos de 90.826 millones de euros a finales de $2013^{19}$.

Actualmente, únicamente conservan su estructura como cajas de ahorro la Caixa Ontinyent y Colonya Caixa Pollença y, si analizamos los resultados financieros recogidos en los documentos contables auditados que se encuentran publicados, concluiremos que en estas dos entidades de crédito no se dará la obligación de transformación en fundación al no concurrir ninguno de los supuestos establecidos en el art. 34.2 de la Ley ni tratarse de cajas de ahorro que estén ejerciendo la actividad financiera de forma indirecta.

17 SÁNCHEZ-CALERO, J., "Ante proyecto...”, cit., p. 325, califica al proceso que hay detrás de la transformación de las cajas de ahorro como una "crisis de crecimiento" de tal suerte que las cajas de ahorro se convertirán en accionistas de un banco y se transformarán en fundaciones bancarias, sometidas a la normativa general en materia de fundaciones, sin tener la fundación la condición de entidad de crédito.

${ }^{18}$ LÓPEZ JIMÉNEZ, J. y NARVÁEZ LUQUE, A., cit., p. 7: “(...) la Ley 26/2013 engarza con el RDL 11/2010 para darle continuidad y completar el esquema del ejercicio indirecto de la actividad financiera. Realmente, como no se puede ocultar, las fundaciones bancarias derivan de las fundaciones de carácter especial del RDL 11/2010. (...) el ejercicio indirecto de la actividad financiera buscó facilitar el acceso por las cajas a recursos de máxima categoría, en igualdad de condiciones que los bancos (...). El RDL 11/2010 abrió la espita del sometimiento de las cajas (o de sus bancos instrumentales) a los mercados, para bien y para mal, poniendo fin a esta Arcadia en la que las cajas habían desarrollado su centenaria actividad financiera y social"; DOMÍNGUEZ MARTÍNEZ, J.M., "La función social de las Cajas de Ahorros en la España de las Autonomías", Extoikos (núm. 2, 2011), p. 79: "La reforma del marco normativo de las Cajas aprobada en julio de 2010 venía a ofrecer un conjunto de alternativas razonables: por una parte, posibilitaba que aquellas Cajas que cumplieran holgadamente con los requerimientos de capital pudiesen preservar el modelo tradicional; por otra, se habilitaban diversas fórmulas que aportaban distintas vías para la captación de recursos propios. De alguna manera, el enfoque adoptado no venía sino a refrendar el concepto de "biodiversidad" imperante en la Unión Europea, en el sentido de no establecer esquemas predeterministas para el ejercicio de la actividad empresarial en ningún sector, incluido el financiero"; MARTÍNEZ MERCADO, M., cit., pp. 152 y ss.

${ }^{19}$ Datos extraídos de CECA, Proceso de Reestructuración. Sector de Cajas de Ahorros. Informe de avances, 14 de febrero de 2014, p. 2, disponible en http://www.cajasdeahorros.es/pdfs/informe.pdf 


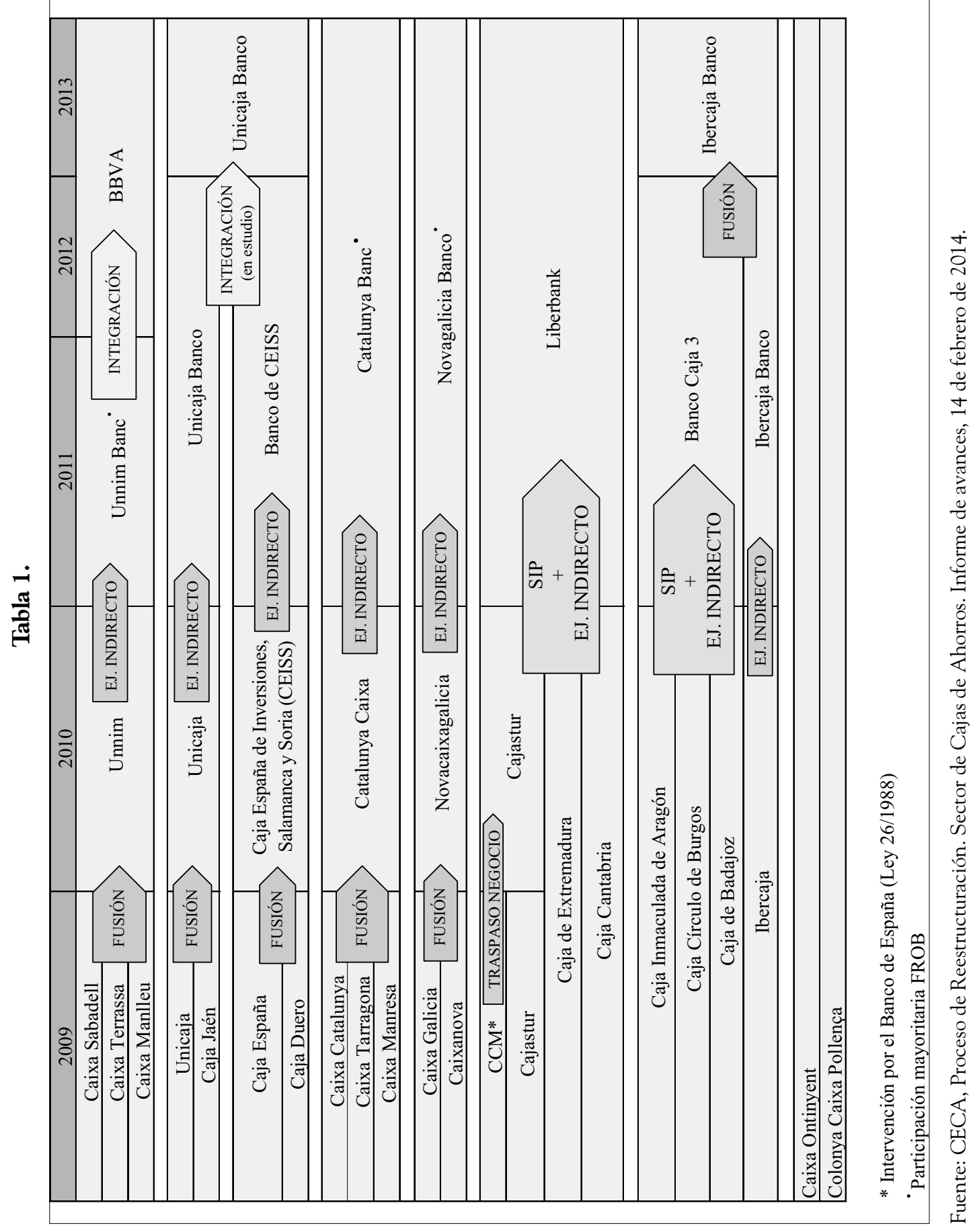




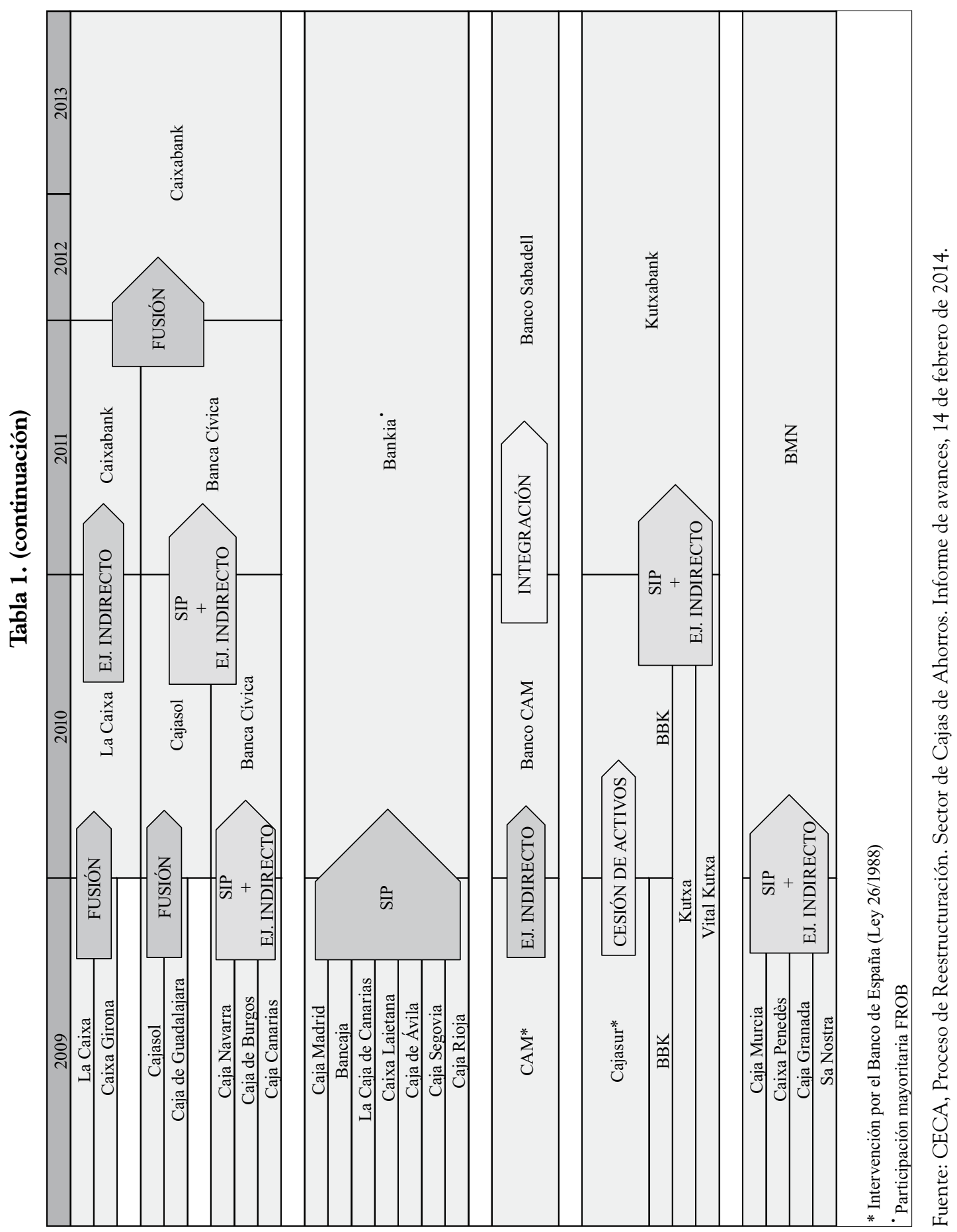

154-170 icade. Revista cuatrimestral de las Facultades de Derecho y Ciencias Económicas y Empresariales, no 92 mayo-agosto 2014, ISSN : 1889-7045 
Por su parte, el resto de cajas de ahorro, integradas ya en bancos al haber traspasado su actividad financiera y, por ello, ejercer la actividad de forma indirecta, deberán proceder a convertirse en fundaciones bancarias u ordinarias tal y como precisa la Exposición de Motivos y la Disposición Transitoria Primera de la Ley ${ }^{20}$. Así, procederá la transformación de estas cajas de ejercicio indirecto en fundaciones bancarias si aquéllas ostentan una participación en una entidad de crédito que alcance, de forma directa o indirecta, al menos un 10\% del capital o los derechos de voto, o bien que le permita nombrar o destituir algún miembro de su órgano de administración.

De esta manera, analizando la información financiera de los grandes bancos en los que se han integrado las cajas de ahorro que ejercen su actividad financiera de modo indirecto, extraemos las siguientes conclusiones:

1. CaixaBank ${ }^{21}$ : En esta entidad financiera, el $64,37 \%$ del capital social está en manos de la Caja de Ahorros y Pensiones de Barcelona (La Caixa). Todo lo demás está diluido entre miles de accionistas, ninguno de ellos llegando al 10\% de manera individualizada. Así, al ostentar La Caixa una participación muy superior al 10\% establecido ex lege, deberá en consecuencia transformarse en fundación bancaria y, dado lo elevado de su participación, superior al 50\%, deberá cumplir determinadas normas adicionales establecidas en la Ley y que se analizarán más adelante. Las otras dos cajas de ahorro, Cajasol y Banca Cívica (compuesta por Caja Navarra, Caja Burgos y Caja Navarra), al ejercer la actividad de modo indirecto, deberán transformarse en fundaciones ordinarias al tener una participación muy reducida en CaixaBank.

2. Bankia ${ }^{22}:$ Su información financiera pone de manifiesto que la entidad está participada al $100 \%$ por el FROB, de tal forma que no cabe analizar la transformación de las cajas de ahorro en este supuesto.

3. Banco Sabadel123: Banco Sabadell absorbió al Banco CAM, entidad de crédito a través de la cual ejercía la actividad financiera de forma indirecta la CAM, caja de ahorro que fue intervenida por el Banco de España. Con la fusión por absorción, Banco CAM fue disuelto sin liquidación y todo su patrimonio se transmitió en bloque a Banca Sabadell. Así, se aprecia cómo la CAM no es accionista de Banco Sabadell, no debiendo en consecuencia entrar a analizar si ha de transformarse en fundación o no.

${ }^{20}$ Sobre la integración de las cajas de ahorro en un SIP y el ejercicio indirecto de la actividad financiera, véase MARTÍNEZ MERCADO, M., cit., pp. 153-155 y LA CASA GARCÍA, R., cit., pp. 19 y ss.

${ }^{21}$ Documentación legal de CaixaBank disponible en http://www.cnmv.es/AUDITA/2013/14921.pdf

22 Documentación legal de Bankia disponible en http://www.cnmv.es/AUDITA/2013/14861.pdf

${ }^{23}$ Documentación legal de Banco Sabadell disponible en http://www.cnmv.es/AUDITA/2013/14860.pdf 
4. Kutxabank ${ }^{24}$ : De su información financiera se extrae que entre su accionariado se encuentra Bilbao Bizkaia Kutxa (BBK) con un 57\% del capital social, Caja de Ahorros y Monte de Piedad de Guipuzkoa y San Sebastián (Kutxa), que ostenta una participación del 32\% y el restante 11\% lo tiene Caja de Ahorros de Vitoria y Álava (Vital). En consecuencia, al superar todas las cajas de ahorro el límite del 10\%, deberán transformarse en fundaciones bancarias, estando BBK y Kutxa sujetas a obligaciones adicionales por su alto grado de participación.

5. Banco Mare Nostrum (BMN) ${ }^{25}$ : Según los últimos documentos auditados (2012), la participación en el capital social de la entidad de crédito es la siguiente: el FROB ostenta un 75,86\%, Cajamurcia un 7,41\%, Caixa Penedés un 5,06\%, Caja Granada un 3,25\%, Sal Nostra un 2,35\% y el resto está disperso en manos de otros accionistas, principalmente, obligacionistas. Consecuentemente, todas estas cajas de ahorro, al no alcanzar los límites previstos en el art. 32 de la Ley, deberán transformarse en fundaciones ordinarias.

6. BBVA $^{26}$ : No existen cajas de ahorro que sean accionistas de BBVA, no pudiendo, en consecuencia, hablar de obligaciones de transformación en este caso.

7. Unicaja Banco ${ }^{27}$ : De la información financiera disponible se advierte que el 100\% del capital social lo ostenta Unicaja (Monte de Piedad y Caja de Ahorros de Ronda, Cádiz, Almería, Málaga, Antequera y Jaén). En consecuencia, Unicaja deberá transformase en fundación bancaria y reportar los documentos e informaciones a que está obligada al tener el control absoluto del banco dentro del cual se ha integrado.

8. Catalunya Banc ${ }^{28}$ : El capital social de este banco está en manos del FROB y del Fondo de Garantía de Depósitos en un 98.4\%, estando la diferencia repartido entre varios accionistas. Entre ellos, se encontrará Catalunya Caixa, la cual deberá transformarse en fundación ordinaria al estar ejerciendo de modo indirecto la actividad financiera pero no llegar a los límites establecidos en la Ley para transformarse en fundación bancaria.

9. NCG Banco ${ }^{29}$ : Según las cuentas anuales de 2012, último ejercicio depositado, el FROB es el accionista único de NCG Banco. Por ello, no procede analizar obligaciones de transformación en este caso.

\footnotetext{
${ }^{24}$ Documentación legal de Kutxabank disponible en http://www.cnmv.es/AUDITA/2013/14948.pdf

${ }^{25}$ Documentación legal de BMN disponible en http://www.cnmv.es/AUDITA/2012/14358.pdf

${ }^{26}$ Documentación legal de BBVA disponible en http://www.cnmv.es/AUDITA/2013/14858.pdf

${ }^{27}$ Documentación legal de Unicaja Banco disponible en http://www.cnmv.es/AUDITA/2013/14936.pdf

${ }^{28}$ Documentación legal de Catalunya Banc disponible en http://www.cnmv.es/AUDITA/2013/14970.pdf

${ }^{29}$ Documentación legal de NCG Banco disponible en http://www.cnmv.es/AUDITA/2012/14303.pdf
} 
10. Liberbank ${ }^{30}$ : Según la información extraída de entre los accionistas más relevantes destacan: Cajastur, con un 69,27\%, Caja de Extremadura con un $13,85 \%$, y Caja Cantabria con un $9,7 \%$. En consecuencia, Cajastur y Caja Extremadura deberán transformarse en fundaciones bancarias al superar los umbrales previstos ex lege. Por su parte, Caja Cantabria se transformará en fundación ordinaria.

11. Ibercaja Banco $^{31}$ : De la información financiera disponible se extrae que su principal accionista es Ibercaja (nombre que recibe la Caja de Ahorros y Monte de Piedad de Zaragoza, Aragón y Rioja) con un 87,8\%, quedando el 12,2\% restante en manos de Fundación Caja de Ahorros de la Inmaculada de Aragón, Fundación Bancaria Caja Círculo y Fundación Caja Badajoz. Por tanto, Ibercaja deberá transformarse en fundación bancaria y cumplir con las obligaciones de información previstas en la Ley para aquellas fundaciones cuya participación supere el $50 \%$ del capital social de la entidad de crédito en la que se integren.

En consecuencia, observamos así cómo la mayoría de las cajas de ahorro que se encuentran ejerciendo su actividad financiera de modo indirecto deberán transformarse en fundaciones bancarias al superar los límites establecidos en el art. 32 de la Ley. En la Tabla 2 siguiente podemos ver un resumen con las cajas transformadas.

Con respecto al procedimiento para proceder a la transformación de las cajas de ahorro, el mismo se regula en el art. 35 de la Ley, pudiendo así extraer las siguientes notas configuradoras:

- La asamblea general de la caja adoptará los acuerdos de transformación en fundación y aprobará los estatutos, designará a sus patronos y llevará a cabo la determinación de los bienes o derechos de la caja que quedarán afectos a la dotación fundacional. Los acuerdos de transformación deberán adoptarse en el plazo de seis meses a contar desde el momento en que se verifique el cumplimiento de alguno de los supuestos del art. 34 .

- Si transcurrido el plazo de los seis meses no ha tenido lugar la transformación, se producirá la disolución directa de todos los órganos de la caja de ahorro y la baja en el registro especial de entidades de crédito del Banco de España, quedando así la caja transformada en fundación bancaria u ordinaria, según proceda.

- El protectorado de la fundación bancaria nombrará una comisión gestora a los efectos de aprobar los estatutos, nombrar los patronos, determinar los bienes o derechos afectos y adoptar cuantos actos o acuerdos sean necesarios.

${ }^{30}$ Documentación legal de Liberbank disponible en http://www.cnmv.es/AUDITA/2013/14924.pdf

${ }^{31}$ Documentación legal de Ibercaja Banco disponible en http://www.cnmv.es/AUDITA/2013/14972.pdf 
- La segregación de la actividad financiera se regirá por la Ley 3/2009, de 3 de abril, sobre modificaciones estructurales de las sociedades mercantiles.

- La transformación, una vez producida, no requerirá ninguna autorización administrativa ulterior.

Tabla 2

\begin{tabular}{|l|c|c|c|}
\hline \multicolumn{1}{|c|}{ Caja } & F. Bancaria & F. Ordinaria & No se transforma \\
\hline Caixa Ontinyent & & & $\mathrm{x}$ \\
\hline Colonya Caixa Pollença & & & $\mathrm{x}$ \\
\hline La Caixa & $\mathrm{x}$ & & \\
\hline Cajasol & & $\mathrm{x}$ & \\
\hline Banca Cívica & & $\mathrm{x}$ & \\
\hline BBK & $\mathrm{x}$ & & \\
\hline Kutxa & $\mathrm{x}$ & & \\
\hline Vital & & $\mathrm{x}$ & \\
\hline Cajamurcia & & $\mathrm{x}$ & \\
\hline Caixa Penedés & & $\mathrm{x}$ & \\
\hline Caja Granada & & $\mathrm{x}$ & \\
\hline Sal Nostra & $\mathrm{x}$ & & \\
\hline Unicaja & & $\mathrm{x}$ & \\
\hline Catalunya Caixa & $\mathrm{x}$ & & \\
\hline Cajastur & $\mathrm{x}$ & & \\
\hline Caja de Extremadura & & $\mathrm{x}$ & \\
\hline Caja Cantabria & $\mathrm{x}$ & & \\
\hline Ibercaja & & & \\
\hline
\end{tabular}

Fuente: Elaboración propia.

Por su parte, la Ley regula también la transformación de fundaciones ordinarias en bancarias. Ésta tiene lugar cuando las fundaciones ordinarias, que son transformaciones de las cajas de ahorro en los supuestos del art. 34 de la Ley que no cumplen los requisitos del art. 32 para ser fundaciones bancarias, adquieren una participación en una entidad de crédito que alcance, de forma directa o indirecta, al menos, un 10\% del capital o de los derechos de voto de la entidad, o que le permita nombrar o destituir a algún miembro de su órgano de administración, es decir, cuando las fundaciones ordinarias cumplen los requisitos establecidos para ser bancarias. Además de esto, también pueden darse casos de fundaciones 
ordinarias, no procedentes de transformaciones de las cajas de ahorro que, si son accionistas de una entidad de crédito y superan los límites del art. 32 de la Ley, deberán también seguir el procedimiento previsto en el art. 36 para transformarse en fundaciones bancarias.

En cualquiera de los casos, si la fundación ordinaria, proceda o no de una transformación previa de una caja de ahorro, adquiere una participación con las características establecidas ex lege, estará obligada a seguir el procedimiento y transformarse en bancaria. En este sentido, el patronato procederá a adoptar los acuerdos de transformación con aprobación de los nuevos estatutos y designación del nuevo patronato. El acuerdo de transformación será comunicado al protectorado para que sea ratificado en el plazo de dos meses, debiendo en todo caso el mismo adoptarse en el plazo general de seis meses desde la formalización de la adquisición de la participación. En caso de no transformarse en plazo, la fundación se extinguirá y se abrirá el procedimiento de liquidación.

En conclusión, se observa cómo las cajas de ahorro verán su naturaleza jurídica modificada al convertirse exclusivamente en fundaciones (ya no entidades de crédito), bancarias u ordinarias, a la vez que en accionistas de las entidades de crédito a las que transfieran sus negocios financieros cuando tenga lugar cualquiera de los supuestos habilitantes para la transformación ${ }^{32}$. De hecho, del análisis realizado, hemos concluido que todas las cajas de ahorro, salvo dos, tendrán que transformarse en fundaciones, bancarias la mayoría y ordinarias el resto. Ello implica que las nuevas fundaciones se centrarán fundamentalmente en dos tareas. Por un lado, gestionarán su participación en la entidad de crédito a la que se traspase la actividad financiera y, por otro, atenderán y desarrollarán las actividades de obra social. En este punto, es interesante poner de manifiesto cómo con el nuevo sistema las fundaciones bancarias se nutrirán principalmente de los dividendos que obtengan de la entidad de crédito de la que sean accionistas, siendo por ello estos recursos los que irán dirigidos a la obra social ${ }^{33}$. Es decir, la obra social desarrollada por las fundaciones bancarias se financiará, principalmente, con cargo a parte de los dividendos obtenidos como remuneración por las acciones poseídas en el capital de la entidad de crédito, de tal suerte que la intensidad

32 Sobre las dificultades que implica la inserción de fundaciones dentro de un grupo de entidades de crédito, véase EMBID IRUJO, J.M., "La inserción de una fundación en un grupo de empresas: problemas jurídicos", Revista de Derecho Mercantil (núm. 278, 2010), pp. 1386 y ss. Por su parte, sobre la modificación de la naturaleza de las cajas de ahorro, véase LA CASA GARCÍA, R., cit., p. 19: "En suma, mediante la aportación efectuada la caja de ahorro en cuestión pasa de ser una genuina fundación-empresa a constituir una fundación poseedora de una participación - de control- en el banco titular del negocio financiero anteriormente perteneciente a dicha caja".

${ }^{33}$ MARTÍNEZ MERCADO, M., cit., pp. 157: "Esta fundación centrará su actividad en la atención y desarrollo de su obra benéfico social, para lo cual podrá llevar a cabo la gestión de su cartera de valores. La fundación deberá destinar a su finalidad benéfico social el producto de los fondos, participaciones e inversiones que integren su patrimonio". 
de esta labor de obra social vendrá marcada por la buena actuación de la entidad financiera participada, salvo que se realicen ciertas ventas de paquetes accionariales o se consiga financiación por otras vías ${ }^{34}$.

Así, para hacer frente a la nueva estructura jurídica, la Ley establece ciertas particularidades en lo que respecta a los órganos de gobierno de las fundaciones bancarias así como ciertos mecanismos de supervisión y control pues, como ya hemos comentado, las fundaciones son actores principales y un funcionamiento inadecuado de las mismas podría afectar al sistema financiero en su conjunto.

\section{EL GOBIERNO DE LAS FUNDACIONES BANCARIAS}

Los órganos de gobierno de las fundaciones bancarias son el patronato, las comisiones delegadas del mismo previstas en los estatutos, el director general y los demás órganos delegados o apoderados del patronato que, en su caso, prevean los estatutos conforme a la normativa general de fundaciones.

Tal y como ocurre en la Ley 50/2002, de 26 de diciembre, de Fundaciones, el patronato es el máximo órgano de gobierno y representación de la fundación bancaria, correspondiéndole al mismo el cumplimiento de los fines fundacionales y la administración de los bienes y derechos que integran el patrimonio. Asimismo, establece el art. 38 de la Ley que será el responsable del control, supervisión e informe al Banco de España.

El patronato estará compuesto por los patronos en el número previsto en los estatutos de la fundación (aunque no podrá sobrepasar los quince miembros) y siempre de acuerdo con el principio de proporcionalidad en función del volumen de sus activos. Los patronos podrán ser personas físicas y jurídicas,

34 LÓPEZ JIMÉNEZ, J. y NARVÁEZ LUQUE, A., cit., p. 13. Asimismo, es interesante traer a colación, a pesar de estar referido al Real Decreto Ley 11/2010, la reflexión que se hace en SÁNCHEZCALERO, J., "El Real Decreto-Ley...”, cit., p. 182: “(...) no resulta menos cierto que algunos defensores del statu quo previo a la reciente reforma [el Real Decreto Ley 11/2010 en este caso] invocaban la obra social como la razón de ser de las cajas, alegando que las propuestas de reforma estaban orientadas a obstaculizar tal labor social. La reforma ha evidenciado la falacia de tal argumento pues, como veremos, ha establecido la plena compatibilidad entre la actividad empresarial propia de toda entidad de crédito y el desarrollo de la citada obra social. Esta última, por mucha que fuera y sea su relevancia, ni era el criterio fundamental y decisivo de la gestión de las cajas, ni conserva esa función diferenciadora. La gestión de las cajas -como la de cualquier otra entidad de crédito- debe cumplir ese mandato de ser sana y prudente, esto es, de anteponer a cualquier otro objetivo el de la solvencia de la entidad como garantía de su continuidad y estabilidad (lo que afectará, entre otros muchos aspectos, a los programas diseñados para la ejecución de la obra social). Sólo a partir de la solvencia cabe plantear esa actuación social, en la que las cajas encuentran, además, una notable competencia por parte de muchas otras entidades. Asistimos a una generalización de la denominada Responsabilidad Social Empresarial o Responsabilidad Social Corporativa, que priva de fundamento la tesis de un acercamiento a estructuras empresariales típicamente mercantiles implique una renuncia a la importante actuación social de las cajas de ahorro". 
relevantes en el ámbito de actuación de la obra social de la fundación bancaria y debiendo pertenecer, en todo caso, a alguno de los grupos establecidos en el art. 39.3 de la Ley ${ }^{35}$. Por su parte, los miembros del patronato deberán reunir los requisitos de honorabilidad comercial y profesional exigidos por la Ley, así como poseer los conocimientos y experiencia específicos para el ejercicio de sus funciones. Además, en la medida en que los patronos ejercen sus funciones en beneficio exclusivo de los intereses de la fundación y del cumplimiento de su función social, los mismos no podrán desempeñar cargos equivalentes en la entidad bancaria de la que la fundación sea accionista ni en otras entidades controladas por el grupo, en caso de haberlo (art. 40.3) ${ }^{36}$. Asimismo, la Ley reproduce el art. 15.4 de la Ley 50/2002, de 26 de diciembre, de Fundaciones, al establecer el carácter gratuito del ejercicio del cargo de patrono con las excepciones previstas para esto.

${ }^{35}$ Estos grupos son: a) Personas o entidades fundadoras, así como las de larga tradición en la caja o cajas de ahorros de que proceda, en su caso, el patrimonio de la fundación bancaria; b) Entidades representativas de intereses colectivos en el ámbito de actuación de la fundación bancaria o de reconocido arraigo en el mismo; c) Personas privadas, físicas o jurídicas, que hayan aportado de manera significativa recursos a la fundación bancaria o, en su caso, a la caja de ahorros de procedencia; d) Personas independientes de reconocido prestigio profesional en las materias relacionadas con el cumplimiento de los fines sociales de la fundación bancaria, o en los sectores, distintos del financiero, en los que la fundación bancaria tenga inversiones relevantes; e) Personas que posean conocimientos y experiencia específicos en materia financiera, que habrán de integrar el patronato en el porcentaje que prevea la legislación de desarrollo de esta Ley, y cuya presencia será representativa y creciente en función del nivel de participación en la entidad de crédito que corresponda.

El patronato debe contar, al menos, con un representante de los grupos a), b), d) y e) anteriores y, siempre que fuera posible identificar una aportación significativa dentro de los quince años anteriores a la constitución del patronato, al menos con un representante del grupo c). A estos efectos, se entenderá por aportación significativa aquella que represente más del $5 \%$ de los recursos propios de la fundación.

Asimismo, el art. 39.4 prevé que el número de patronos representantes de administraciones públicas y entidades y corporaciones de derecho público no podrá superar el $25 \%$ del total.

${ }^{36}$ No obstante lo previsto en el art. 40.3, se observa cómo la Ley dulcifica esa dureza primera a través de la Disposición Transitoria Segunda. En efecto, la mencionada disposición prevé una compatibilidad temporal para aquellas personas que, a la entrada en vigor de la Ley, sean miembros simultáneamente de los consejos de administración de la caja de ahorro y de la entidad bancaria a través de la cual la primera ejerce indirectamente su actividad financiera. Así, se permite temporalmente la compatibilidad pero sujeta a una serie de límites: i) En ningún caso podrán ejercerse funciones ejecutivas en el banco y en la fundación; ii) El número de miembros compatibles en la entidad de crédito no podrá exceder del $25 \%$ de los miembros de su consejo de administración; y iii) La compatibilidad de cada miembro se mantendrá hasta que agote su mandato en curso a la entrada en vigor de la Ley en la entidad bancaria, y en todo caso no más tarde del 30 de junio de 2016. Sobre la incompatibilidad, véase HIDALGO ROMERO, R. y PIAZZA DOBARGANES, L., cit., p. 33: "Esta incompatibilidad (...) supone el fin de prácticas consistentes en replicar la estructura de cargos en los órganos de gobierno de las cajas de ahorros y sus bancos participados, suponiendo un importante límite a los derechos de las fundaciones en cuanto socios de control o referencia de las entidades de crédito en las que participan". En el mismo sentido, CALVO VÉRGEZ, J., "Las nuevas exigencias de saneamiento y de gobierno corporativo en la futura ley de cajas: luces y sombras", Actualidad Jurídica Aranzadi (núm. 864, 2013), versión electrónica (BIB 2013/1206), p. 2, si bien este autor plantea si no hubiese sido más conveniente limitar la incompatibilidad exclusivamente a los cargos ejecutivos. 
Los estatutos regularán los procesos de designación de los patronos, el número y duración de los mandatos así como las comisiones delegadas del patronato, en caso de haberlas. La Ley viene a establecer, en este punto, una limitación, y es que los patronos que pertenezcan al grupo de las personas independientes de reconocido prestigio profesional en las materias relacionadas con el cumplimiento de los fines sociales de la fundación bancaria, o en los sectores, distintos del financiero, en los que la fundación bancaria tenga inversiones relevantes (art. 39.3.d), no podrán ejercer el cargo durante más de dos mandatos consecutivos y, en todo caso, por un plazo superior a doce años.

Por último, señalar que el presidente del patronato será elegido de entre sus miembros, correspondiéndole la más alta representación de la fundación bancaria. Al director general lo nombrará el patronato, tendrá voz pero no voto y no podrá ser un patrono. Además, se nombrará un secretario que podrá ser o no patrono, en cuyo caso tendrá voz pero no voto y a quien corresponderá la certificación de todos los acuerdos adoptados por el patronato ${ }^{37}$.

Se observa de toda esta regulación cómo la Ley pretende consolidar un marco en el que las fundaciones bancarias actúen con los niveles de profesionalidad, transparencia, independencia y eficiencia máximos en tanto en cuanto que se tratan de actores significativos del sistema crediticio español y, por ello, su actuación debe ser cuidadosa. Se trata, pues, de acabar con la mala imagen de unas cajas de ahorro reconvertidas en fundaciones bancarias en las que la influencia política y la degeneración del ejercicio de esa influencia han acabado por rodear a las mismas de un aura de desprestigio colectivo. La profesionalización de las estructuras de gobierno, ya iniciada a través del Real Decreto Ley 11/2010, y continuada a través de la Ley, apunta a la conveniencia de frenar esos excesos y de superar el tópico de que las fundaciones bancarias son "el feliz retiro donde recalan fieles distinguidos de uno u otro partido" 38 .

\section{ELEMENTOS DE SUPERVISIÓN Y CONTROL DE LAS FUNDACIONES BANCARIAS}

\subsection{Protocolo de gestión de la participación financiera}

El art. 43 de la Ley prevé que aquellas fundaciones bancarias que posean una participación igual o superior al 30\% del capital en una entidad de crédito o una participación tal que les permita controlar a la misma, elaborarán, de forma individual o conjunta, un protocolo de gestión de la participación fi-

\footnotetext{
${ }^{37}$ RUBIO TORRANO, E., cit., p. 3.

38 SÁNCHEZ-CALERO, J., "El Real Decreto-Ley...", cit., p. 184.
} 
nanciera ${ }^{39}$. A estos efectos, precisa la norma que se entenderá como una única participación la de todas las fundaciones, ordinarias o bancarias, que actúen de forma concertada en una misma entidad de crédito, debiendo por ello preparar, de forma conjunta, el protocolo de gestión. Se trata pues de introducir una medida de supervisión de aquellas entidades que, por lo elevado de su participación en el capital, ejercen un alto grado de control sobre una entidad bancaria, para evitar así las graves consecuencias que se podrían derivar de una mala gestión de esa participación.

El protocolo de gestión, cuyo contenido mínimo será precisado por el Banco de España, deberá contener, al menos, los siguientes aspectos:

- Los criterios básicos de carácter estratégico que rigen la gestión de la participación de control por parte de la fundación bancaria.

- Las relaciones entre el patronato de la fundación y los órganos de gobierno de la entidad de crédito participada, con especial referencia a los criterios de elección de consejeros.

- Los criterios generales para la realización de operaciones entre la fundación bancaria y la entidad de crédito participada así como los mecanismos para evitar conflictos de interés.

Este documento deberá ser elaborado por el patronato de la fundación y remitido al Banco de España para su valoración y posterior aprobación, teniéndose muy en cuenta la influencia de la fundación bancaria en la gestión sana y prudente de la entidad participada. El protocolo se hará público y se revisará, al menos anualmente, por el Banco de España, órgano responsable de la supervisión de la entidad de crédito participada.

\subsection{Plan financiero}

Además de la elaboración del protocolo de gestión, las fundaciones bancarias que se encuentren en la misma situación que el apartado anterior deberán presentar anualmente al Banco de España un plan financiero en el que se ponga de manifiesto la manera en la que harán frente a posibles necesidades de capital en que pudieran incurrir las entidades de crédito participadas así como los criterios básicos de su estrategia de inversión en entidades financieras. El Banco de España valorará el plan financiero atendiendo a la posible influencia de la fundación ban-

39 SÁNCHEZ-CALERO, J., “Anteproyecto...", cit., p. 325: "Este documento [el protocolo de gestión] supone una novedad en nuestro panorama bancario, puesto que constituye una suerte de convenio entre el accionista (la fundación bancaria) y la sociedad participada (banco) con respecto al uso que se va a hacer de esa participación, a la presencia en los órganos de gobierno del banco de los representantes de la fundación y, finalmente, a los criterios de posibles operaciones entre ambos". 
caria sobre la gestión sana y prudente de la entidad participada al ser el supervisor de esta clase de entidades.

El contenido mínimo del plan financiero será especificado por el Banco de España, debiendo en cualquier caso contener, al menos, los siguientes extremos:

- Estimaciones razonables de necesidades de recursos propios de la entidad participada en distintos escenarios macroeconómicos.

- Estrategia de la fundación para obtener dichos recursos en cada escenario.

- Criterios básicos de la estrategia de inversión en entidades de crédito.

Como se observa, se trata éste de otro mecanismo de control previsto para las fundaciones bancarias en consonancia con la importancia que les atribuye la Ley en relación con el sistema financiero.

Adicionalmente, se establece que las fundaciones bancarias que posean una participación igual o superior al $50 \%$ en una entidad de crédito o una que les permita el control de la misma deberán acompañar el plan financiero de los siguientes instrumentos ${ }^{40}$ :

a) Un plan de diversificación de inversiones y de gestión de riesgos, en el cual se incluyan compromisos para que la inversión en activos emitidos por una misma contraparte, diferentes de aquellos que presenten elevado grado de liquidez y solvencia, no supere los porcentajes máximos sobre el patrimonio total, en los términos establecidos por el Banco de España.

b) La dotación de un fondo de reserva para hacer frente a posibles necesidades de recursos propios de la entidad de crédito participada que no puedan ser cubiertas con otros recursos y que, a juicio del Banco de España, puedan poner en peligro el cumplimiento de las obligaciones en materia de solvencia ${ }^{41}$. A tal fin, el plan financiero contendrá un calendario de dotaciones mínimas hasta alcanzar el volumen objetivo que determine el Banco de España en función de una serie de factores. Por otra parte, la constitución del fondo de reserva no será preceptiva en los casos en los que se incorporen al plan de diversificación un programa de desinversión que incluya con detalle las medidas a implementar por la fundación para reducir su participación en la entidad de crédito por debajo del $50 \%$ en un plazo máximo de 5 años ${ }^{42}$.

${ }^{40}$ CALVO VÉRGEZ, J., cit., pp. 1-2.

${ }^{41}$ Este fondo de reserva deberá invertirse en instrumentos financieros de elevada liquidez y calidad crediticia, los cuales deberán estar en todo momento plenamente disponibles para su uso por la fundación. Los supuestos y el modo de uso del fondo será determinado por el Banco de España, debiendo en todo caso hacerse uso del mismo en caso de disminución significativa de los recursos propios de la entidad participada y siempre y cuando esta disminución pudiera poner en peligro el cumplimiento de la normativa de solvencia a juicio del regulador.

${ }^{42}$ CALVO VÉRGEZ, J., cit., p. 2, se pregunta hasta qué punto la creación del fondo de reserva podría terminar mermando la obra social, si bien concluye que ello dependerá de si se permiten derivar ingresos que no sólo procedan de dividendos, tales como participaciones en otras compañías. 
c) Cualquier otra medida que, a juicio del Banco de España, se considere necesaria para garantizar la gestión sana y prudente de la entidad participada y la capacidad de ésta de cumplir de forma duradera con las normas de ordenación y disciplina que le sean aplicables.

\subsection{Ampliación de capital y distribución de dividendos en entidades participadas}

Las Disposiciones Adicionales Octava y Décima contienen medidas que restringen la libertad de actuación de las fundaciones bancarias con una participación igual o superior al $50 \%$ o que les permita controlar a la entidad de crédito participada. En este sentido, las fundaciones con los niveles de participación referidos que acudan a procesos de ampliación de capital de las entidades participadas no podrán ejercer los derechos políticos correspondientes a aquella parte del capital adquirido que les permita mantener una posición igual o superior al 50\% o de control. Ahora bien, el Banco de España podrá exceptuar la aplicación de esta medida en aquellos casos en que la entidad bancaria se halle en algún proceso de actuación temprana, reestructuración o resolución, los cuales, por su parte, podrán incluir la obligación de las fundaciones bancarias de no aumentar o de reducir su participación a los efectos de no tomar posiciones de control.

Por su parte, los acuerdos de reparto de dividendos de las entidades participadas por esta clase de fundaciones bancarias estarán sujetos al quórum de constitución reforzado y deberán adoptarse por mayoría de, al menos, dos tercios del capital presente o representado en la junta ${ }^{43}$. Los estatutos de la entidad de crédito participada podrán elevar esta mayoría.

Con este conjunto de medidas, la Ley promueve que las fundaciones bancarias reduzcan paulatinamente su participación en las entidades de crédito a fin de que el proceso de reestructuración del sistema financiero español concluya en un período de tiempo razonable, lo cual está en consonancia con las exigencias del Memorando de Entendimiento.

\subsection{Control por las Administraciones Públicas}

Las normas que regulan expresamente el régimen de control de las fundaciones bancarias se encuentran recogidas en el Título II, Capítulo V, arts. 45-47 de la Ley, contemplando el control por parte del protectorado, del Banco de España y un régimen sancionador en caso de incumplimiento de las obligaciones de aportación de información ${ }^{44}$.

${ }^{43}$ CALVO VÉRGEZ, J., cit., p. 2, critica por considerarlo "excesivo y no justificado", el quórum de constitución reforzada así como la mayoría necesaria para la aprobación del acuerdo de reparto de dividendos.

${ }^{44}$ En concreto, el art. 47 de la Ley dispone la calificación como infracción muy grave a los supuestos de incumplimiento de las obligaciones del capítulo IV, es decir, las obligaciones de presentación del pro- 
Por lo que respecta al control ejercido por parte del protectorado, se prevé que éste velará por la legalidad de la constitución y funcionamiento de las fundaciones bancarias, sin perjuicio de las funciones que corresponden al Banco de España. Para aquellas fundaciones bancarias cuyo ámbito de actuación principal exceda el de una Comunidad Autónoma, el protectorado será ejercido por el Ministerio de Economía y Competitividad. Por el contrario, el protectorado lo ejercerá la Comunidad Autónoma correspondiente. Expresamente prevé la Ley que para el ejercicio de las funciones de protectorado previstas en el art. 35.1 c), e), f) y g), de la Ley 50/2002, de 26 de diciembre, de Fundaciones, por parte del Ministerio de Economía y Competitividad, será necesario que éste recabe el informe previo de las Comunidades Autónomas en las que la fundación bancaria desarrolle su obra social ${ }^{45}$.

Por su parte, el Banco de España adquiere un papel muy importante en el régimen de control de las fundaciones bancarias en la medida en que es el órgano encargado de la supervisión de las entidades de crédito participadas por aquéllas en virtud de lo previsto en la Ley 26/1988, de 29 de julio, sobre Disciplina e Intervención de las Entidades de Crédito, todo ello en orden a valorar la influencia de las fundaciones bancarias sobre la gestión sana y prudente de la entidad de crédito. En este sentido, al Banco de España le corresponde el control del cumplimiento de las normas previstas para aquellas fundaciones bancarias con participaciones superiores al 30 y al 50\%, es decir, las fundaciones bancarias que están obligadas a presentar el protocolo de gestión de la participación financiera y el plan financiero así como las especialidades previstas para las fundaciones que ostenten una participación de control (plan de diversificación de inversiones y de gestión de riesgos, fondo de reserva y demás medidas necesarias a juicio del Banco de España).

Así, para realizar sus labores de supervisión y control, el Banco de España va a poder realizar las inspecciones y comprobaciones que considere oportunas además de poder requerir a la fundación bancaria cuanta información resulte necesaria para desarrollar sus funciones.

tocolo de gestión de la participación financiera, del plan financiero y demás medidas para las fundaciones bancarias que tengan una participación igual o superior al $50 \%$ o que les permita el control de la entidad de crédito participada.

${ }^{45}$ En este sentido, las funciones que necesitarán el previo informe autonómico son: (i) asesorar a las fundaciones ya inscritas sobre su régimen jurídico, económico-financiero y contable, así como sobre cualquier cuestión relativa a las actividades por ellas desarrolladas en el cumplimiento de sus fines, prestándoles a tal efecto el apoyo necesario; (ii) velar por el efectivo cumplimiento de los fines fundacionales, de acuerdo con la voluntad del fundador, y teniendo en cuenta la consecución del interés general; (iii) verificar si los recursos económicos de la fundación han sido aplicados a los fines fundacionales, pudiendo solicitar del patronato la información que a tal efecto resulte necesaria, previo informe pericial realizado en las condiciones que reglamentariamente se determine; y (iv) ejercer provisionalmente las funciones del órgano de gobierno de la fundación si por cualquier motivo faltasen todas las personas llamadas a integrarlo. 


\subsection{Obligaciones de gobierno corporativo}

Por último, señalar que la Ley prevé que las fundaciones bancarias hagan público, con carácter anual, un informe de gobierno corporativo que, como mínimo, contendrá los siguientes extremos:

- Estructura, composición, funcionamiento y determinación de la política de nombramientos de los órganos de gobierno.

- Política de inversión en la entidad bancaria: descripción del ejercicio de los derechos correspondientes a la participación accionarial durante el ejercicio.

- Otras inversiones: actuaciones y política seguida.

- Mecanismos para evitar que la política de remuneraciones implique la asunción de riesgos excesivos y remuneraciones percibidas por el patronato, individual o colectivamente, y la dirección general, en su caso.

- Operaciones vinculadas.

- Política de conflictos de interés.

- Actividad de la obra social desarrollada.

El informe será comunicado y enviado copia del mismo al protectorado de tal suerte que la falta de elaboración o de publicación, así como la existencia de omisiones o de datos falsos o engañosos, conllevará las sanciones de multa por importe de hasta el 0,5\% de los recursos propios de la fundación o hasta 500.000 euros si aquel porcentaje fuera inferior a esta cifra, así como una amonestación pública con publicación en el BOE.

\section{CONCLUSIONES}

De todos los aspectos tratados en el presente trabajo podemos concluir que toda la regulación de la nueva Ley está encaminada a mantener un sistema financiero sostenido, con entidades de crédito saneadas de tal suerte que no lleguen a alcanzar unos niveles demasiado grandes como para llegar a ser sistémicos, cumpliéndose así con las exigencias previstas en el Memorando de Entendimiento. Asimismo, es objetivo de la Ley reducir al máximo la presencia de cajas de ahorro en el panorama financiero y controlar y supervisar a los nuevos actores de la escena, las fundaciones bancarias, las cuales podrán llegar a ser, como de hecho ocurrirá, accionistas con un alto poder en aquellas entidades de crédito en las que participen como consecuencia del traspaso de todo su patrimonio afecto a la actividad financiera a esa entidad de crédito participada. De hecho, del análisis desarrollado se aprecia cómo muchas de las nuevas fundaciones bancarias habrán de ostentar participaciones muy elevadas, e incluso de control, en los bancos de 
los que son accionistas, debiendo por ello cumplirse con firmeza los mecanismos de supervisión y control previstos en la Ley para evitar así injerencias de la fundación en la gestión de la entidad de crédito resultante.

De esta forma, en el nuevo panorama financiero existirán grandes bancos en cuyo accionariado se integrarán las cajas de ahorro ya transformadas en fundaciones, bancarias u ordinarias, las cuales estarán centradas en la gestión de su participación y en el desarrollo de las actividades de obra social. La financiación de éstas se hará vía dividendos recibidos como remuneración por la participación de las fundaciones en las entidades financieras en las cuales se integren, dependiendo por tanto la intensidad de la obra social de la buena marcha del banco en cuestión. Así, al depender la obra social de la buena marcha de la entidad financiera en cuestión y del posible reparto de dividendos, se puede prever una posible disminución de los fondos disponibles destinados para estas actividades, perjudicándose, en consecuencia, a la sociedad en su conjunto, toda vez que son muchas y muy variadas las actividades de obra social que las cajas de ahorro venían realizando.

Como se ha apuntado, la regulación establece un esquema en cascada, estableciendo distintos niveles de supervisión y control a medida que la participación de la fundación bancaria en la entidad de crédito aumenta, asumiendo obligaciones diferentes que van desde la presentación de un protocolo de gestión y un plan financiero, hasta un plan de diversificación de inversiones y la dotación de un fondo de reserva para hacer frente a posibles necesidades de recursos propios de la entidad de crédito. Asimismo, se establecen limitaciones respecto a la posibilidad de adquirir nuevas acciones en ampliaciones de capital, lo cual conecta con la intención de que se vaya produciendo una progresiva desinversión de estas entidades en los bancos de los que son accionistas, todo ello en un contexto de sometimiento a un riguroso régimen de supervisión por parte del protectorado y del Banco de España.

En nuestra opinión, si bien todas estas medidas merecen ser aplaudidas por pretender la gestión sana y prudente de las entidades de crédito que permanecen en el sector tras la reestructuración financiera acometida en nuestro país, consideramos que habría que ponderar y valorar el nivel de exigencia de la Ley con las exigencias impuestas por las instancias comunitarias e internacionales y plasmadas en el Memorando de Entendimiento, pues en cierto punto las medidas de la primera podrían ser bastante más restrictivas que las solicitadas hasta el punto de poner en peligro el ejercicio del derecho de propiedad de la fundación sobre el banco participado con el objetivo de garantizar una gestión independiente y profesional de éste.

Por último, destacar el nuevo régimen de composición del patronato, el cual busca la absoluta profesionalización del órgano de gobierno y la ausencia de injerencia de políticos en estas fundaciones, a la vez que se prevé la total incom- 
patibilidad entre el ejercicio de cargos en la fundación bancaria y en la entidad financiera. En efecto, a pesar de esta incompatibilidad, el control que la fundación ejercerá sobre el banco en cuestión será muy grande dados los niveles de participación accionarial en algunos casos, lo cual pone de manifiesto la especial importancia de los mecanismos establecidos de supervisión y control. No tendría ningún sentido que las cajas de ahorro se transformen en fundaciones para separar la actividad financiera de la obra social si en el panorama actual siguen controlando aquéllas el negocio financiero de los bancos en los cuales se integran.

\section{BIBLIOGRAFÍA}

ARAGÓN REYES, M. y otros, El régimen jurídico de las Cajas de Ahorros, Caja Madrid, Madrid, 1991.

CALVO VÉRGEZ, J., "Las nuevas exigencias de saneamiento y de gobierno corporativo en la futura ley de cajas: luces y sombras", Actualidad Jurídica Aranzadi (núm. 864, 2013), versión electrónica (BIB 2013/1206), pp. 1-4.

CAÑABATE POZO, R., El régimen jurídico de la fusión de Cajas de Ahorros, Unicaja-Marcial Pons, Madrid-Barcelona, 2006.

CECA, Proceso de Reestructuración. Sector de Cajas de Ahorros. Informe de avances, 14 de febrero de 2014, disponible en http://www.cajasdeahorros. es/pdfs/informe.pdf

Memoria sobre la Obra Social en 2012, disponible en http://www.ceca.es/rsc/ pdfs/Memoria_OBS2012.pdf

DIEZ-PICAZO, L., "Sobre la naturaleza jurídica de las cajas de ahorro", Revista jurídica Universidad Autónoma de Madrid (núm. 8, 2003), pp. 199-213.

DOMÍNGUEZ MARTÍNEZ, J.M., "La función social de las Cajas de Ahorros en la España de las Autonomías", Extoikos (núm. 2, 2011), pp. 77-79.

EMBID IRUJO, JM., "La inserción de una fundación en un grupo de empresas: problemas jurídicos”, Revista de Derecho Mercantil (núm. 278, 2010), pp. 1373-1400.

"El ejercicio de actividades empresariales por las fundaciones (fundación-empresa y fundación con empresa): su significado en el régimen jurídico de las Cajas de Ahorros en España", Perspectiva del Sistema Financiero (núm. 91, 2007), pp. 29-73.

HIDALGO ROMERO, R. y PIAZZA DOBARGANES, L., "Consideraciones preliminares sobre la regulación proyectada de las fundaciones bancarias", Revista Aranzadi Doctrinal (núm. 11, 2013), pp. 27-36.

LA CASA GARCÍA, R., "Los modelos de organización institucional de las cajas de ahorro", Revista de Derecho Bancario y Bursátil (núm. 131, 2013), pp. 7-33. 
LEÓN SANZ, F.J., "La reestructuración del sistema financiero español: la transformación de las Cajas de Ahorro", en Las reformas de las sociedades cotizadas y del sistema financiero 2008-2009, Monografías Coediciones Aranzadi, Aranzadi, 2014, versión electrónica (BIB 2014/5110), pp. 1-24.

LÓPEZ JIMÉNEZ, J. y NARVÁEZ LUQUE, A., "Ley de Cajas de Ahorros y Fundaciones Bancarias: la expulsión de las cajas de su paraíso financiero", Diario La Ley (núm. 8246, 7 de febrero de 2014), versión electrónica (LA LEY 140/2014), pp. 1-25.

MARTÍNEZ MERCADO, M., "Las cajas de ahorro: propiedad y ejercicio de las cuotas participativas ante el RD 11/2010. ¿Fin de su naturaleza jurídica?, Revista de Derecho Bancario y Bursátil (núm. 121, 2011), pp. 137-160.

RUBIO TORRANO, E., "Fundaciones bancarias y cajas de ahorros", Revista Doctrinal Aranzadi Civil-Mercantil (núm. 6, 2013), versión electrónica (BIB 2013/1559), pp. 1-3.

SÁNCHEZ-CALERO, J., "Anteproyecto de Ley de cajas de ahorro y fundaciones bancarias", Revista de Derecho Bancario y Bursátil (núm. 129, 2013), pp. 324-326.

"El Real Decreto-Ley 11/2010 y la "mercantilización" de las cajas", Revista de Derecho Bancario y Bursátil (núm. 121, 2011), pp. 173-187.

TITOS MARTÍNEZ, M., "La Obra Social de las Cajas de Ahorros y sus perspectivas de futuro”, Extoikos (núm. 8, 2012), pp. 67-72 